Nevertheless, we can expect that by virtue of their immature coordination and judgment the accident rate in children will be particularly high, especially among the unsupervised riders. Since these motorcycles are being ridden off the road accidents are less likely to involve a second vehicle-indeed, about one third of motorcycle accidents on public roads result from riders falling off their machines, but are no less damaging for that."

Can it be wise to permit children as young as 6 to ride machines of $50 \mathrm{cc}$ and over at speeds of up to 40 miles an hour? Rather than permit the unrestricted sale of motorcycles designed for children, would it not be more responsible to restrict their sale to recognised clubs for use at official meetings only and to raise the lower age limit? Should we not ensure that a medical officer is present at all such meetings and that accidents causing injury are fully documented in order that safety measures in force may be evaluated?

Motorcycling is potentially a most dangerous sport and is probably not appropriate for children under the age of 12: unsupervised, the riding of motorbikes by children of any age is quite unacceptable and should be outlawed.

M A MASON

Senior Registrar,

Accident and Emergency Department,

Northampton General Hospital,

Northampton NN1 8BD

1 Royal Society for the Prevention of Accidents. 1982 road accident statistics. London: Royal Society for the Prevention of Accidents, 1984:4.

Woodward A. Motorcycle accidents in Nottinghamshire. Public Health 1984;97:139-48. Transport and Road Research Laboratory. Injuries to unprotected road users. Crowthorn: Transpor
and Road Research Laboratory, 1979. (Leaflet No LF 792.)

\title{
Replacement of surfactant in hyaline membrane disease
}

\begin{abstract}
If hyaline membrane disease is due entirely to surfactant deficiency, as is widely believed, it should be amenable to replacement treatment. Indeed, attempts at replacement of surfactant have been made for 20 years, ${ }^{12}$ but encouraging results have been obtained only recently. The practical problems may be summarised in four questions: What should be given as replacement? How much should be given? How should it be administered? and When is it best given?
\end{abstract}

The first question begs another: what is pulmonary surfactant? Natural surfactant lipoprotein is made up roughly of $45 \%$ dipalmitoyl phosphatidyl choline, $20 \%$ phosphatidyl choline containing unsaturated fatty acids, $6 \%$ phosphatidyl glycerol, $5 \%$ protein, $12 \%$ other phospholipids, and $9 \%$ neutral lipids. ${ }^{34}$ But an adequate answer to the question requires further detail of the physical states through which natural surfactant passes in its cycle of secretion and reabsorption. ${ }^{4}$ Surfactant is manufactured by alveolar type II cells and is stored intracellularly in osmophilic lamellar bodies. ${ }^{4}$ These bodies are secreted into the thin layer of liquid which coats the alveoli, where they unravel and recombine to form tubular myelin. ${ }^{5}$ The unique structure of tubular myelin (long lipid walled tubes of square cross section which are closely packed together) is seen only in natural surfactants containing physiological concentrations of calcium. ${ }^{\circ}$ The specific surfactant apolipoprotein may be necessary for the structure of tubular myelin, a notion which is supported by the fact that dipalmitoyl phosphatidyl choline binds the apolipoprotein preferentially.

The extremely rapid adsorption of natural surfactant to an air-liquid surface is due, probably, to some of the lipids being in the form of tubular myelin. ${ }^{6}$ The structure may be nature's way of prepackaging the hydrophobic "tails" and hydrophilic polar "heads" of the phospholipids in large continuous sheets (the walls of the tubes) so that the lipid can adsorb to a surface with less energy and thus faster than if the lipids were in the form of liposomes. ${ }^{8}$ After a period of "aging" the lipids desorb from the surface monolayer and form liposomes or vesicles, which are recycled by the type II alveolar cell or ingested by alveolar macrophages. ${ }^{9}$ (By no means are all of these concepts universally held: some think that tubular myelin is an inactivated form of surfactant ${ }^{10}$; others that the surfactant monolayer is not applied on an aqueous hypophase but directly on to the epithelial cells of the lung. ${ }^{11}$ )

To return, then, to the first question: What is the best surfactant to use clinically? The answer must take account not only of the constituents but also of the adsorption rate of the mixture and its ability to give consistently very low surface tensions on repeated dynamic compression of a surface monolayer in vitro; perhaps even a note on its ultrastructure should be included. If the scheme of events described above is correct then tubular myelin, the immediate precursor of the surface monolayer which is found only in natural surfactants, would be the "best" surfactant to use. Natural surfactants, however, contain protein (plasma proteins as well as the apolipoprotein, all of which might be antigenic), so paediatricians have been understandably reluctant to use animal surfactants in babies, preferring synthetic or artificial mixtures containing only lipids.

Dipalmitoyl phosphatidyl choline, the main constituent of surfactant, is a solid at temperatures up to $41^{\circ} \mathrm{C}$ and adsorbs hardly at all to an air-liquid surface. The addition of other lipids, particularly phosphatidyl glycerol and some containing unsaturated fatty acid side chains, may lower the temperature at which the dipalmitoyl phosphatidyl choline will adsorb and spread on a surface.12 "Dry" (solid) surfactant, a mixture of dipalmitoyl phosphatidyl choline and phosphatidyl glycerol in powder form, circumvents the adsorption hurdle by spreading extremely rapidly (in vitro), provided that it is delivered from the air side of an air-liquid surface. ${ }^{8}$ Adsorption of dipalmitoyl phosphatidyl choline from the aqueous phase may also be enhanced by the addition of plasma high density lipoprotein ${ }^{12}$ and surfactant apolipoprotein, ${ }^{72}$ though this action has been disputed. ${ }^{13}$ Unfortunately, even at best, the adsorption from an aqueous phase of synthetic surfactants, ${ }^{12}$ and even of lipids extracted from natural surfactants and therefore containing hardly any protein, ${ }^{14}$ is two orders of magnitude slower than of natural surfactant containing tubular myelin, which adsorbs within seconds. ${ }^{6}$

These facts help to explain why the results of clinical trials of synthetic surfactants have been disappointing. ${ }^{12} 15$ Nevertheless, Morley et al claimed that babies treated with "dry" surfactant fared better than an untreated group ${ }^{16}$; but the trial was poorly controlled, and two other small clinical studies of the same dry surfactant showed no effect. ${ }^{17} 18$ Morley and his coworkers have abandoned surfactant in powder form and are currently assessing the effect of a cold aqueous slurry of "dry" surfactant. A different synthetic 
surfactant used by Halliday et al in a well controlled trial produced no difference between treated and untreated babies $^{19}$-but their novel surfactant mixture containing human plasma high density lipoprotein adsorbs over 100 times more slowly than natural surfactant.

Naturally derived surfactant is superior to artificial mixtures in preventing and treating hyaline membrane disease in animal models. ${ }^{15}$ Natural bovine surfactant, extracted with organic solvents which reduce but do not eliminate completely the protein component, has been used in two centres. Although a dramatic and permanent clinical improvement in 10 babies was described by Fujiwara et al,,$^{20}$ and a definite but temporary improvement in six babies was reported by Smyth et al, ${ }^{21}$ neither trial was controlled, so that there is no convincing evidence that the improvement can be ascribed solely to the surfactant. The obvious step of treating babies with unextracted natural human surfactant (harvested, in this case, from amniotic liquid) has been taken by Hallman et al. ${ }^{3}$ The results of their small trial (10 babies in all, including five controls) were encouraging, showing improved gas exchange and decreased ventilator support after administration of surfactant.

How much surfactant should be given? In premature lambs natural surfactant at a dose of $50 \mathrm{mg} \mathrm{lipid} / \mathrm{kg}$ body weight was found to be optimal in treating hyaline membrane disease over the first few hours of life, ${ }^{22}$ and human surfactant in a dose of $60 \mathrm{mg} / \mathrm{kg}$ appeared to work for eight to 15 hours in the babies treated by Hallman et al. ${ }^{3}$ Whether repeated doses are needed in the normal course of hyaline membrane disease is not clear. The theoretical requirement of $0.7 \mu \mathrm{g}$ dipalmitoyl phosphatidyl choline/ $\mathrm{cm}^{2}$ to produce a complete monolayer over the alveolar surface area is equivalent to less than $7 \mathrm{mg}$ dipalmitoyl phosphatidyl choline for a neonatal human or lamb. ${ }^{23}$ Much of the discrepancy between calculated and practical requirements is probably due to natural surfactant preparations containing only $45 \%$ dipalmitoyl phosphatidyl choline; they are also likely to contain poorly surface active lipids in the form of degraded surfactant and perhaps other contaminating lung lipids which are unrelated to the function of surfactant. ${ }^{9}$ Tubular myelin, which may be the main active component of natural surfactant, constitutes merely one quarter of the total lipid as estimated by area on electron micrographs. ${ }^{6}$

How surfactant should be delivered to babies depends on what is given. If natural surfactant is chosen then a concentrated suspension in saline should be instilled into the trachea. It appears that "lumps" of natural surfactant in suspension enhance adsorption and that homogenisation reduces this effect (B Benson, personal communication). This is further evidence that the physical state of the lipoprotein complex is crucial to function. Other methods of administration have included insufflation of powder, squirts of aerosols, nebulisation, and intratracheal instillation of ultrasonicated suspension of lipid. The preparation of some of these mixtures and their modes of delivery may well have diminished any benefit they originally had. ${ }^{24}$ Deposition of surfactant in the oropharynx of rabbit pups before the first breath is effective, but there are no data on the effect in larger animals and babies. ${ }^{26}$

The timing of replacement may be important. Areas of the bronchiolar epithelium become necrotic within minutes of birth in hyaline membrane disease. ${ }^{27}$ Sooner or later shear forces or local overdistension rupture the pulmonary epithelium, and plasma proteins enter the air spaces. The efficacy of natural surfactant in vitro and in vivo is reduced by plasma proteins, but the fact that the surfactant can be repurified and shown to be chemically and functionally unchanged suggests that reversible binding to an inhibitor, perhaps a protein, may occur. ${ }^{28}$ Thus it would be best to give surfactant at birth before epithelial damage has occurred. In the trial of Hallman et al, however, beneficial effects were produced even at 6 hours of age. ${ }^{3}$ Not enough clinical information has been gained to decide on the optimal or practical time for treatment.

Several caveats should be mentioned. Firstly, successful treatment with surfactant seems to be associated with a high incidence of patent ductus arteriosus. ${ }^{20} 29$ This may simply be a function of the lowered pulmonary vascular resistance in treated hyaline membrane disease associated with immaturity of the ductal smooth muscle. Secondly, not all respiratory distress is due to deficiency of surfactant, and no amount of exogenous surfactant will make up for immature anatomical development, or for immaturity of the mechanism responsible for absorption of liquid from the fetal lung. ${ }^{30}$ Thirdly, there are practical problems in ensuring that natural surfactant, including that of human origin, is free of pathogens. Fourthly, we do not know the long term immunological sequelae of treatment with natural human or animal surfactant.

Hence currently no variety of surfactant replacement treatment in hyaline membrane disease can be strongly recommended. Synthetic surfactants have not produced convincing beneficial effects. Natural surfactants are the best treatment for hyaline membrane disease in animals, and a small clinical trial of unmodified human surfactant, the only one published to date, has produced results which should encourage further studies.

DAFYDD V WALTERS

Senior Lecturer and Consultant Paediatrician,

University College London,

Rayne Institute,

London WClE 6JJ

1 Robillard E, Alarie Y, Dagenais-Perusse P, Baril E, Builbeault A. Microaerosol administratio of synthetic dipalmitoyl lecithin in the respiratory distress syndrome: a preliminary report. Can Med Assoc $\mathcal{F}$ 1964;90:55-7.

2 Chu J, Clements JA, Cotton E, Klaus MH, Sweet AY, Tooley WH. Neonatal pulmonary ischemia. Part I. Clinical and physiological study. Pediatrics 1967;40:709-82.

Hallman M, Merritt TA, Schneider H, et al. Isolation of human surfactant from amniotic fluid and a pilot study of its efficacy in respiratory distress syndrome Pediatrics 1983;71:473-82. Goerke I. Lung surfactant. Biochim Biophy

myelin in alveoli of fetal rat lungs. I Cell Biol 1977;72:260-77.

Gorke J Sargeant T. Role of calcium ions in the structure and function of pulmonary surfactant. Biochim Biophys Acta 1984;793:18-27.

King RJ, Macbeth MC. Physiochemical properties of dipalmitoyl phosphatidyl choline after interaction with an apolipoprotein of pulmonary surfactant. Biochim Biophys Acta 1979;557 86-101.

8 Morley CJ, Bangham AD, Johnson P, Thorburn GD, Jenkin G. Physical and physiological properties of dry lung surfactant. Nature 1978;271:162-3.

Magoon MW, Wright JR, Baritussio A, et al. Subfractionation of lung surfactant. Implication for metabolism and surface activity. Biochim Biophys Acta 1983;750:18-31.

10 Massaro D, Clerch L, Temple D, Baier H. Surfactant deficiency in rats without a decreased amount of extracellular surfactant. $\mathcal{f}$ Clin Invest 1983;71:1536-43.

11 Hills BA. What is the true role of surfactant in the liung? Thorax 1981;36:1-4.

Meban C. Effect of lipids and other substances on the adsorption of dipalmitoyl phosphatidyl choline. Pediatr Res 1981;15:1029-31.

. Pulmonary surfactant-associated proteins: their role in the expression of surface activity. F Appl Physiol 1980;49:34-41.

Egan EA, Notter RH, Kwong MS, Shapiro DL. Natural and artificial lung surfactan replacement in premature lambs. $\mathcal{J}$ Appl Physiol 1983;55:875-83.

1980;158:57-68.

6 Morley CJ, Bangham AD, Miller N, Davis JA. Dry artificial lung surtactant and its effect on very premature babies. Lancet $1981 ;$ i:64-8

Wilkinson AR, Jeffery JA, Jenkins PA. Controlled ial of dry surfactant in preterm infants. Arch Dis Child 1982;57:802. (Abstract.)

8 Milner AD, Vyas $\mathrm{H}$, Hopkin TE. Effects of artificial surfactant on lung function and blood gase in idiopathic respiratory distress syndrome. Arch Dis Child 1983;58:458-60.

Halliday H, Reid MMcC, Meban C, McClure G, Lappin TRJ, Thomas PS. Controlled trial of artificial surfactant to prevent respiratory distress syndrome. Lancet 1984;i:476-8.

Fujiwara T, Chida S, Watabe Y, Maeta H, Morita T, Abe T. Artificial surfactant therapy in hyaline membrane disease. Lancet $1980 ; 1: 55-9$

. Enhorning G. Hyaline membrane

Ikegami $\mathrm{M}$, Adams $\mathrm{FH}$, Towers $\mathrm{B}$, Osher $\mathrm{AB}$. The quantity of natural surfactant necessary to prevent the respiratory distress syndrome in premature lambs. Pediatr Res 1980;14:1082-5.
Mescher EJ, Platzker ACG, Ballard PL, Kitterman JA, Clements JA, Tooley WH. Ontogeny o tracheal fluid, pulmonary surfactant and plasma corticoids in the fetal lamb. $\mathcal{J}$ Appl Physio 1975;39:1017-21. 
24 Notter RH, Smith S, Taubold RD, Finkelstein JN. Path dependence of adsorption behavior of

mixtures containing dipalmitoyl phosphatidyl choline. Pediatr Res 1982;16:515-9.
25 Notter RH, Shapiro DL. Lung surfactant in an era of replacement therapy. Pediatrics

26 Enhorning G, Roberton B, Milne E, Wagner R. Radiological evaluation of the premature newborn rabbit after pharyngeal deposition of surfactant. Am $\mathcal{O}$ Obstet Gynecol 1975;121:47580 .

27 Nilsson R, Grossman G, Robertson B. Bronchiolar epithelial lesions induced in the premature rabbit neonate by short periods of artificial ventilation. Acta Pathol Microbiol Immunol Scand

28 Ikegami M, Jobe A, Glatz T. Surface activity fo

premature lambs.

( after surtactant replacement therapy. F Pedratr 1982;100:101-7.

30 Brown MJ, Olver RE, Ramsden CA, Strang LB, Walters DV. Effects of adrenaline and of spontaneous labour on the secretion and absorption of lung liquid in the fetal lamb. $\mathcal{F}$ Physiol 1983;344:137-52.

\section{Sepsis and cholestasis}

Paediatricians know that in neonates cholestatic jaundice may be the sole manifestation of a serious infection, particularly with Gram negative organisms. The association used to be recognised in adults, too-for example, with lobar pneumonia 1 - but it has become uncommon. A recent case report of gangrenous appendicitis presenting as cholestatic jaundice has highlighted the diagnostic dilemma. ${ }^{2}$

Cholestatic jaundice is most often due to mechanical obstruction of the biliary tract both inside and (more commonly) outside the liver, but it may also occur if for any reason conjugated bilirubin cannot be secreted from the liver cell or if flow along the canaliculi and fine bile channels is impeded. In such cases the cause might still be said to be "microscopic" obstruction to the secretory apparatus, but the number and variety of associations, which include inherited syndromes, pregnancy, many drugs, haemolysis, burns, operations, and sepsis, suggest that a single mechanistic explanation is unlikely. For the clinician the important point is that the key to diagnosis may lie elsewhere than in the biliary system, and an error may cost the patient dear, especially if cholestasis is the dominant feature.

The association with sepsis has been described repeatedly. ${ }^{134}$ Fever, rigors, and other signs of infection are followed within a few days by a mild to moderate obstructive jaundice without pain or itching. Alternatively, the doctor trying to make a diagnosis in a patient with unexplained malaise or fever may be surprised to find that the results of liver function tests suggest obstruction. Usually the serum concentration of bilirubin is moderately raised, up to perhaps six times normal $(100 \mu \mathrm{mol} / \mathrm{l} ; 5 \cdot 8 \mathrm{mg} / 100 \mathrm{ml})$; exceptions are possible with both normal and very high values mimicking extrahepatic obstruction being recorded. ${ }^{56} \mathrm{~A}$ useful pointer in the absence of clinical jaundice is bilirubinuria. The activity of alkaline phosphatase is almost always raised, as are concentrations in the serum of substances such as bile acids and sulphobromophthalein that are usually excreted in the bile, while serum aminotransferase activities are normal or only mildly raised. Where liver biopsy specimens have been obtained the picture is characteristic of intrahepatic cholestasis, with bile in canaliculi around the central veins and in liver cells, a mild inflammatory cell response, and minimal hepatocellular damage. Material obtained at biopsy is invariably sterile on culture.

If occult sepsis is not borne in mind conditions such as cholangitis, liver abscess, Weil's disease, and tropical infections are likely to be considered. Where there is septicaemia (and results of blood cultures are by no means always positive), the organisms isolated have included Escherichia coli, Klebsiella pneumoniae, and Haemophilus influenzae ${ }^{4}$; but probably infection with any organism-and Legionella is one of the latest to be reported ${ }^{7}$-may result in cholestasis.
Among the recorded sites of infection have been the appendix, diverticula, the kidneys and lungs, endocarditis, and pelvic and subphrenic abscesses. A proper appreciation of the cause of the jaundice may be delayed because some patients are already suffering from the effect of operation, shock, haemolysis, and anoxia and may have been given multiple blood transfusions and potentially hepatotoxic drugs.

Many theories, none of them satisfactory, have been put forward to account for this type of cholestasis, ranging from the effect of bacterial endotoxins to local obstruction from inflammatory cells and swollen Kupffer cells. A much simpler explanation could be that a form of inspissated bile syndrome is induced by changes in the relative amounts of water, electrolytes, and larger molecules in the bile itself from factors such as fever, dehydration, and hypotension. Whatever the mechanism this type of cholestasis offers no threat to the patient provided that its identity is recognised; it does not require elaborate investigation. The clinical lesson to be learnt is that if an obstructive pattern of liver function values in seriously ill patients cannot be confidently attributed to disease of the liver or gall bladder a dangerous intruder must be sought in another part of the body.

\section{Alex Paton}

Postgraduate Dean,

North East Thames Region,

British Postgraduate Medical Federation,

London WC1 3EJ

1 Tugwell $\mathrm{P}$, Williams AO. Jaundice associated with lobar pneumonia. A clinical, laboratory and histological study. Qf Med 1977;46:97-118.

Meyer G, Landi JP, Pitchumoni CS. Acute appendicitis presenting as cholestatic jaundice. $N Y$ Stale Med 1984;84:131-2.

, Webber BL, Saunders SJ. Jaundice in severe bacterial infection. Gastro-

inmerman $\mathrm{HJ}$, Fang $M$, Utili R et al. Jaundice due to bacterial infection. Gastroenterolo 1979;77:362-74.

Neale G, Caugley DE, Mollin DL, Booth CC. Effects of intrahepatic and extrahepatic infection on liver function. $\mathrm{BrMed} \mathcal{F} 1966 ; \mathrm{i}: 382-7$.

Elev DF, Hargreaves T, Lambert HP. Jaundice in severe infections. Br Med f 1965;ii:75-7. Kirby BD, Snyder KM, Meyer RD, Finegold SM. Legionnaire's disease: clinical features of 24 cases. Ann Intern Med 1978;89:297-309.

\section{Cysticercosis: a new hope}

Effective treatments are still needed for many infectious disorders common in the developing world, so a recent paper from Mexico is welcome in holding out a definite promise of such a treatment for cysticercosis. ${ }^{1}$

Cysticercosis is produced when man becomes the host of the larval stages of the pig tapeworm Taenia solium. In the normal life cycle the adult worm lives in the human small intestine, and the eggs (or intact gravid segments of the worm) leave the body in the faeces. When the eggs are swallowed by pigs they hatch out to release oncospheres, : which penetrate the gut wall and are carried by the circulation to the various tissues of the body, where they encyst as "bladder worms." Cysts may be found almost anywhere but are particularly abundant in the skeletal muscles and myocardium. When the pig's muscle is infected by these cysts the pork is said to be measly. Man becomes infected with the adult worms by eating inadequately cooked measly pork.

Adult tapeworms in the gut cause few symptoms apart from the uncomfortable sensation caused by an escaping proglottid. The serious effects of $T$ solium are produced when man becomes host to the bladder worms (cysticerci). This may come about when he eats the eggs or by internal 